\title{
Intraocular eyelashes and iris cyst in anterior chamber following penetrating eye injury: a case report
}

\author{
Sabin Sahu' \\ Lila Raj Puri' \\ Sanjay Kumar Singh ${ }^{2}$ \\ 'Department of Ophthalmology, \\ Sagarmatha Choudhary Eye Hospital, \\ Lahan, Siraha, ${ }^{2}$ Department of \\ Ophthalmology, Biratnagar Eye \\ Hospital, Biratnagar, Nepal
}

This article was published in the following Dove Press journal:

International Medical Case Reports Journal

22 March 2017

Number of times this article has been viewed

Background: The presence of intraocular eyelashes following penetrating eye injury or ocular surgery is relatively uncommon. The response of the eye to intraocular eyelashes is variable. The eyelash may be symptomatic or may remain asymptomatic for long periods.

Objective: We report a case with two intraocular eyelashes and an iris cyst after 2 years of asymptomatic period following penetrating eye injury.

Case presentation: A 24-year-old male presented with decreased vision in the left eye which he had noticed for the previous 2 weeks. His visual acuity was $6 / 6$ in the right eye and $6 / 18$ in the left eye, improving to $6 / 9$ with $-2.5 \mathrm{DC} \times 140^{\circ}$ correction. The intraocular pressure was $12 \mathrm{mmHg}$ in both eyes. On slit-lamp examination, the left eye showed $8 \mathrm{~mm}$ linear peripheral corneal opacity nasally, two eyelashes in the superior anterior chamber, and an iris cyst measuring $4 \mathrm{~mm} \times 4 \mathrm{~mm}$ in the superior iris. The right eye was normal. Dilated fundus examination of both eyes was normal. The eyelashes and cyst were removed surgically. There were no complications during the 3-month follow-up period.

Conclusion: Intraocular implantation of eyelashes following penetrating eye injury can remain asymptomatic for long periods; however, late development of iris cyst may occur.

Keywords: intraocular eyelashes, iris cyst, penetrating eye injury

\section{Introduction}

The presence of intraocular eyelashes following penetrating eye injury or ocular surgery is relatively uncommon. It has been reported to occur secondary to penetrating eye injury, ${ }^{1-3}$ ocular surgery, ${ }^{4-6}$ or even without apparent etiology. ${ }^{7,8}$ The response of the eye to intraocular eyelashes is variable. The eyelash may remain asymptomatic for long periods ${ }^{9,10}$ or may be symptomatic. ${ }^{4,11}$ We report an uncommon case with coexistence of two intraocular eyelashes and a secondary iris cyst after 2 years of asymptomatic period following penetrating eye injury.

\section{Case report}

A 24-year-old Nepalese male presented with decreased vision in the left eye noticed for last 2 weeks. His visual acuity was $6 / 6$ in the right eye and $6 / 18$ in the left eye, improving to $6 / 9$ with $-2.5 \mathrm{DC} \times 140^{\circ}$ correction. The intraocular pressure was $12 \mathrm{mmHg}$ in both eyes. On slit-lamp examination, the left eye showed $8 \mathrm{~mm}$ linear peripheral corneal opacity nasally. In the anterior chamber, two curvilinear foreign bodies were seen superiorly resembling eyelashes, and an iris cyst measuring $4 \mathrm{~mm} \times 4 \mathrm{~mm}$ was seen (Figure 1). The anterior chamber was quiet, and there was no posterior synechia. Gonioscopy examination revealed normal angle structures and no foreign bodies.
Correspondence: Sabin Sahu Sagarmatha Choudhary Eye Hospital, Lahan-3, Siraha, Nepal

Tel +97798 62223692

Fax+97733560492

Email sabinsahu@gmail.com 


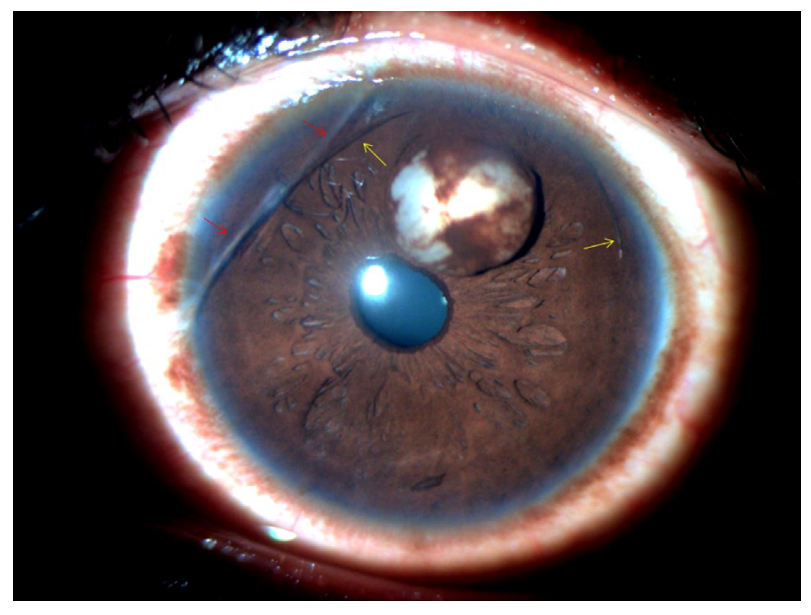

Figure I Slit-lamp photograph of the anterior segment at presentation showing iris cyst, two eyelashes in the anterior chamber (yellow arrows) and linear corneal opacity (red arrows).

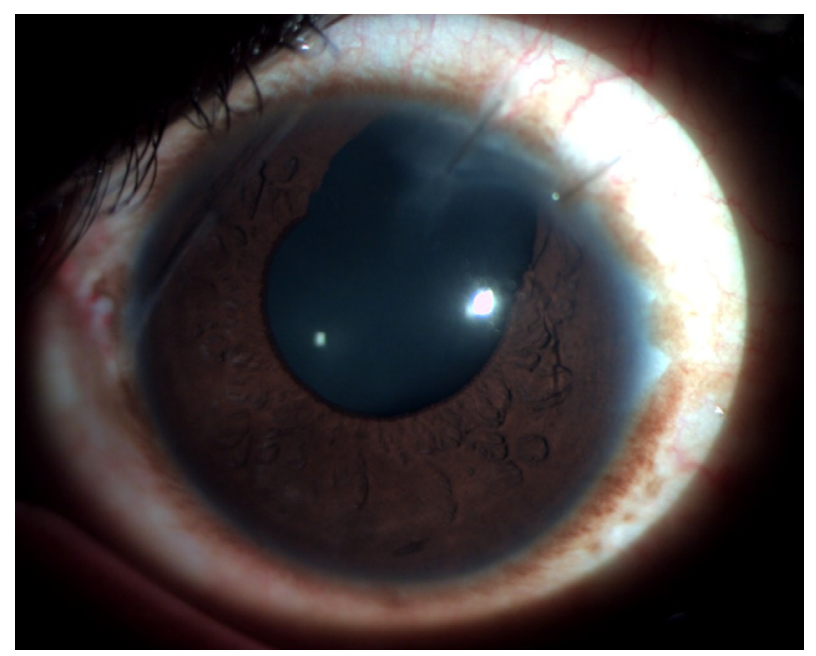

Figure 2 Slit-lamp photograph of the anterior segment I week postoperatively showing the sectoral surgical iridectomy.

The pupil appeared slightly oval but was reacting normally to light. Lens was clear, and dilated fundus examination did not reveal any abnormality. The right eye was normal. Ocular history revealed past history of trauma in the left eye with a metallic wire while working in a construction site abroad 2 years back. No medical care was sought at that time. There was no history of past ocular surgeries.

The eyelashes and the iris cyst were removed surgically. The anterior chamber was entered at the superotemporal limbus, and viscoelastic substance was introduced. The lashes were removed, and the cyst was excised in toto with a sectoral iridectomy. There was no collateral damage to other ocular structures. Postoperatively, there was transient anterior segment inflammation and microscopic hyphema, which subsided with topical antibiotic-steroid combinations. The visual acuity in the left eye eventually improved to $6 / 6$ with
$-1.5 \mathrm{DC} \times 130^{\circ}$ correction. The patient did not complain of glare despite the broad iridectomy (Figure 2). There were no complications in the 3-month follow-up period.

\section{Discussion}

The intraocular eyelashes are usually well tolerated and remain asymptomatic due to their relatively inert nature compared to other organic materials and the immune-privileged feature of the eye. ${ }^{12}$ The posttraumatic intraocular cilia have been reported to remain silent for 50 years. ${ }^{10}$ The intraocular eyelashes may be associated with corneal edema, granulomatous inflammation, cyst formation, intralenticular abscess, retinal detachment, endophthalmitis and even sympathetic ophthalmia. ${ }^{3,412-14}$ Various treatment modalities have been described for treatment of iris cyst with varying outcomes. Small and asymptomatic cysts may be closely observed, while the larger cysts require surgical management. ${ }^{15}$ Conservative surgical approaches such as aspiration of the cyst have been described but are associated with a high rate of recurrence. ${ }^{16}$ Intracystic injections of low-dose anti-mitotic agents have also been found useful in recurrent secondary iris cyst. ${ }^{17}$ Needle aspiration and endodiathermy treatment of epithelial inclusion cyst of the iris have also been reported to have a good result. ${ }^{18}$ Lasers play an important role in the management of iris cysts. Lasers can be used alone or in conjunction with other treatment modalities of the iris cyst. Laser iridotomy of the cyst offers a noninvasive method of therapy for posttraumatic iris inclusion cysts but is associated with a high rate of recurrence. ${ }^{19}$ Viscoelastic dissection of the posttraumatic iris cyst has been described with an acceptable long-term outcome. ${ }^{20}$ Viscoelastic-assisted endophotocoagulation has been documented to have an excellent response in the management of secondary iris cysts. ${ }^{21}$ Various other forms of surgical excision include sector iridectomy, iridectomy plus cryotherapy, iridocyclectomy, iridectomy with corneal curettage and posterior corneal lamellar dissection. ${ }^{22}$ In our case, sector iridectomy was done to excise the iris cyst in toto along with the intraocular eyelashes removal through the limbal approach. Viscoelastic substance was used so that the cyst could be excised with minimal trauma to the corneal endothelium and adjacent ocular structures. The postoperative visual outcome was good, and there were no significant complications associated with the procedure.

\section{Conclusion}

Intraocular implantation of eyelashes following penetrating eye injury can remain asymptomatic for a long period; however, late development of iris cyst may occur. Various surgical techniques, ranging from minimally invasive laser procedures 
to extensive surgical procedures, have been described with variable outcomes. We report a relatively uncommon case with coexistence of two intraocular eyelashes and a secondary iris cyst after 2 years of asymptomatic period following penetrating eye injury and its successful management with intraocular eyelashes removal and sector iridectomy.

\section{Acknowledgments}

Written informed consent for the publication of the case report and images was obtained from the patient. The authors' thanks go the patient for permitting them to report this case, and to Mr Dipesh Ram for helping with the patient interaction and clinical photography.

\section{Author contributions}

SS examined and managed the patient, reviewed the literature and drafted the manuscript. LRP diagnosed and managed the case and supervised and drafted the manuscript. SKS critically analyzed the manuscript and offered valuable suggestions. All authors contributed toward data analysis, drafting and critically revising the paper, gave final approval of the version to be published, and agree to be accountable for all aspects of the work.

\section{Disclosure}

The authors report no conflicts of interest in this work.

\section{References}

1. Hoh $\mathrm{H}$, Menage M. Iris cysts after traumatic implantation of an eyelash into the anterior chamber. Br J Ophthalmol. 1993;77(11):741-742.

2. Köse S, Kayikçioğlu O, Akkin C, Yağci A, Basdemir G. Coexistence of intraocular eyelashes and anterior chamber cyst after penetrating eye injury: a case presentation. Int Ophthalmol. 1994-1995;18(5):309-311.

3. Gopal L, Banker AS, Sharma T, Parikh S, Bhende PS, Chopra S. Intraocular cilia associated with perforating injury. Indian J Ophthalmol. 2000;48(1):33-36.

4. Galloway GD, Ang GS, Shenoy R, Beigi B. Retained anterior chamber cilium causing endophthalmitis after phacoemulsification. $J$ Cataract Refract Surg. 2004;30(2):521-522.
5. Islam N, Dabbagh A. Inert intraocular eyelash foreign body following phacoemulsification cataract surgery. Acta Ophthalmol Scand. 2006;84(3):4324.

6. Walker NJ, Hann JV, Talbot AW. Postoperative cilium entrapment by clear corneal incision. J Cataract Refract Surg. 2007;33(4):733-734.

7. Oh KT-(Kean), Oh KT-(Kong), Singerman LJ. An eyelash in the vitreous cavity without apparent etiology. Ophthalmic Surg Lasers. 1996;27(3):243-245.

8. Kertes PJ, Al-Ghamdi AA, Brownstein S, Coupal D, Gilberg S, Britton WA Jr. An intraocular cilium of uncertain origin. Can J Ophthalmol. 2004;39(3):279-281.

9. Kargi SH, Oz O, Erdinc E, Teke MY, Firat E. Tolerated cilium in the anterior chamber. Ocul Immunol Inflamm. 2003;11(1):73-78.

10. YalnizAkkaya Z. Posttraumatic cilia remaining inert in the anterior chamber for 50 years: a case report. J Med Case Rep. 2011;5:527.

11. Taneja S, Arora R, Yadava U. Fingernail trauma causing corneal laceration and intraocular cilia. Arch Ophthalmol. 1998;116(4):530-531.

12. Humayun M, de la Cruz Z, Maguire A, Dangel ME, Stark WJ, Green WR. Intraocular cilia. Report of six cases of 6 weeks' to 32 years' duration. Arch Ophthalmol. 1993;111(10):1396-1401.

13. Gottlieb F, Finestone J, Ackerman JL. Intravitreal cilia and retinal detachment. Ann Ophthalmol. 1982;14(6):541-544.

14. Dettoraki M, Andreanos K, Davou S, Nomikarios N, Moschos MM, Brouzas D. Intravitreal cilium associated with retinal detachment 40 years following penetrating eye injury: a case report. BMCOphthalmol. 2015;15:25.

15. Haller JA, Stark WJ, Azab A, Thomsen RW, Gottsch JD. Surgical management of anterior chamber epithelial cysts. Am J Ophthalmol. 2003;135(3):309-313.

16. Shields JA, Shields CL, Lois N, Mercado G. Iris cysts in children: classification, incidence, and management. $\mathrm{Br} J$ Ophthalmol. 1999;83(3):334-338.

17. Kawaguchi K, Yamamoto S, Nagae Y, et al. Treatment of recurrent giant iris cyst with intracyst administration of mitomycin C. Br JOphthalmol. 2000;84(7):800-801.

18. Tsai JC, Arrindell EL, O'Day DM. Needle aspiration and endodiathermy treatment of epithelial inclusion cyst of the iris. Am J Ophthalmol. 2001;131(2):263-265.

19. Gupta V, Rao A, Sinha A, Kumar N, Sihota R. Post-traumatic inclusion cysts of the iris: a long term prospective case series. Acta Ophthalmol Scand. 2007;85(8):893-896.

20. Al-Ghadeer H, Al-Towerki AE, Al-Rajhi A, Al-Awad A. Longterm follow-up and visual outcome after excision of a traumatic iris cyst by viscoelastic dissection. Int Ophthalmol. 2011;31(6):529-531.

21. Lockington D, Altaie R, Moore S, McGhee CN. Successful management of secondary iris cysts with viscoelastic-assisted endophotocoagulation. JAMA Ophthalmol. 2014;132(3):354-356.

22. Rao A, Gupta V, Bhadange Y, Sharma R, Shields JA. Iris cysts: a review. Semin Ophthalmol. 2011;26(1):11-22.
International Medical Case Reports Journal

\section{Publish your work in this journal}

The International Medical Case Reports Journal is an international, peer-reviewed open-access journal publishing original case reports from all medical specialties. Previously unpublished medical posters are also accepted relating to any area of clinical or preclinical science. Submissions should not normally exceed 2,000 words or

\section{Dovepress}

4 published pages including figures, diagrams and references. The manuscript management system is completely online and includes a very quick and fair peer-review system, which is all easy to use. Visit $\mathrm{http}: / / \mathrm{www}$. dovepress.com/testimonials.php to read real quotes from published authors. 